\title{
Human Influences on Tree Diversity and Composition of a Coastal Forest Ecosystem: The Case of Ngumburuni Forest Reserve, Rufiji, Tanzania
}

\author{
J. Kimaro ${ }^{1}$ and L. Lulandala ${ }^{2}$ \\ ${ }^{1}$ Tanzania Wildlife Research institute, P.O. Box 661, Arusha, Tanzania \\ ${ }^{2}$ Department of Forest Biology, Sokoine University of Agriculture, P.O. Box 3032, Morogoro, Tanzania \\ Correspondence should be addressed to J. Kimaro; jegaki@hotmail.com
}

Received 19 June 2013; Revised 8 September 2013; Accepted 2 October 2013

Academic Editor: Kristiina Vogt

Copyright (C) 2013 J. Kimaro and L. Lulandala. This is an open access article distributed under the Creative Commons Attribution License, which permits unrestricted use, distribution, and reproduction in any medium, provided the original work is properly cited.

This paper reports on the findings of an ecological survey conducted in Ngumburuni Forest Reserve, a biodiversity rich forest reserve within the coastal forests of Tanzania. The main goal of this study was to determine the influence of uncontrolled anthropogenic activities on tree species diversity and composition within the forest ecosystem. It was revealed that economic activities including logging, charcoaling, and shifting cultivation were the most important disturbing activities affecting ecological functioning and biodiversity integrity of the forest. Further to this, we noted that the values of species diversity, composition, and regeneration potential within the undisturbed forest areas were significantly different from those in heavily disturbed areas. These observations confirm that the ongoing human activities have already caused size quality degradation of useful plants, enhanced species diversification impacts to the forest ecosystem, and possibly negatively affected the livelihoods of the adjacent local communities. Despite these disturbances, Ngumburuni forest reserve still holds important proportions of both endemic and threatened animal and plant species. The study suggests urgent implementation of several conservation measures in order to limit accessibility to the forest resources so as to safeguard the richness and abundance of useful biodiversity stocks in the reserve.

\section{Introduction}

Habitat loss, fragmentation, and degradation are currently the most important threats to biodiversity conservation worldwide [1]. Human activities have been widely reported to contribute more to this problem compared to natural factors [2]. Tropical forests especially those located in developing countries are more vulnerable following the fact that the majority of forest adjacent communities are poor and depend directly on the forest resources to sustain their livelihood [3]. Unsustainable use of forest resources, for example, through logging and shifting cultivation, has potential impact on its ecological functioning due to sudden changes on their structure and composition [4]. Emergence of invasive species and loss of ecosystem services resulting from the occurrence of many woody pioneers and herbaceous species have been observed in several disturbed forest ecosystems $[1,5]$. Opening of forest canopies in the logged or burnt forests increases light levels which in some cases positively influences diversity indices [6]. Understanding the factors related to human disturbance that affect the tree biodiversity and forest vegetation structure can help conservation managers to suggest best forest management practices in ways that can best protect these values [7].

Ngumburuni Forest Reserve is one of the important biodiversity hotspots in Tanzania [8] that are surrounded by local communities whose livelihoods depend mostly on the forest resources [9]. Following the current poor forest management practices in the Ngumburuni Forest Reserve (NFR), its natural resource-base is likely to become more severely deteriorated in the near future [10]. Earlier studies have reported various interactions between the surrounding 
communities and forest resources in Ngumburuni $[8,11,12]$, but detailed scientific information that indicates how this dependence affects the tree biodiversity is still lacking. This study was, therefore, conducted to fill in this information gap. It is anticipated that answers from this study will be important for developing sustainable management plans for NFR and other forest ecosystems within the coastal area of Tanzania.

\section{Materials and Methods}

2.1. Study Area. Ngumburuni Forest Reserve is located in Rufiji District, Coast Region, Tanzania, between $7^{\circ} 38^{\prime}-7^{\circ}$ $48^{\prime} \mathrm{S}$ and $38^{\circ} 52^{\prime}-39^{\circ} 6^{\prime} \mathrm{E}$ (Figure 1). With elevation of $200 \mathrm{~m}$ above the mean sea level, the forest covers about 10000 ha. Average annual rainfall varies from $900 \mathrm{~mm}$ to $1400 \mathrm{~mm}$, with significant daily, monthly, and annual fluctuations; temperatures range between 24 and $31^{\circ} \mathrm{C}$ with the average of $26^{\circ} \mathrm{C}$ [11]. The main economic activities of the adjacent communities are agriculture and various forest dependent activities. The vegetation of the study area is characterized by four easily distinguished ecological units which include the coastal, Miombo woodland, and riverine forests [11] composed of several tree species with high level of plant species endemism [13]. Similarly, several species of endemic mammals and birds are found in the coastal forests [11].

2.2. Data Collection. Ecological, forest inventory, and socioeconomic surveys were conducted to collect data for this study. Ecological data, for example, vegetation structure, were collected using the latest Landsat TM Satellite image, which permitted the identification and mapping of major ecological features and other land uses. The subscenes of the study area were subjected to visual interpretation and identified land cover/use changes were digitized on screen using the ArcView software. Visual image interpretation was complemented with ground truthing survey while the GPS equipment was used to mark the positions of forest boundaries and other useful features like trail roads and most disturbed forest areas. Based on the conservation status of the forest, we grouped the vegetation covers into two major categories, namely, disturbed and undisturbed strata. The disturbed stratum involved all areas of the forest where anthropogenic activities were dominant, while undisturbed stratum involved the rest of forest areas that were not degraded.

The forest inventory exercise was conducted to establish sample plots, where we proceeded with developing transects and laying out plots on the map of the forest. To cover the whole woodland area and variation between vegetation covers, we adopted the systematic sampling design according to [14] who recommended that systematic sampling design increases the chances of including all vegetation types in the woodland. Because of time constraints and limited resources, we established only two transects one within the disturbed area close to Mkupuka and Mangwi villages and the other one within undisturbed stratum close to Muyuyu village. Sample plots were calculated based on the following formula: $n=T^{2} \cdot \mathrm{CV}^{2} / e^{2}$; where $T$ is $t$-value at given probability level and degree of freedom (taken as 2), CV is coefficient of variation, and $e$ is degree of error. The $\mathrm{CV}$ of 0.5 was adopted since this forest has a similar condition to that of Miombo woodland [15]. Similarly the sampling error of 0.15 was considered sufficient since the level of precision is within acceptable limits of natural forests. According to [15], sampling intensity within a range of $0.5 \%$ to $0.7 \%$ for tropical natural forest inventories is recommended. Therefore, the number of sample plots $(n)$ was $=4 \times 0.25 / 0.0225=44$. An equal number of plots (i.e., 22 replications) were distributed in each transect at an interval of $50 \mathrm{~m}$. We used circular shaped sample plots because they are easy to use and also reduce edge effects and counting errors [16]. Each sample plot was subdivided into three concentric subplots of $2 \mathrm{~m}, 5 \mathrm{~m}$, $10 \mathrm{~m}$, and $15 \mathrm{~m}$ radii whereby the following information were collected.

(a) Within the inner $2 \mathrm{~m}$ radius, number and names of all regenerant species were recorded.

(b) Within the inner $5 \mathrm{~m}$ radius, all trees and shrubs with $\mathrm{DBH} \geq 4 \mathrm{~cm}$, their local and botanical names and frequencies of occurrence were recorded.

(c) Within the inner $10 \mathrm{~m}$ radius, all trees and shrubs with $\mathrm{DBH} \geq 10 \mathrm{~cm}$, their local and botanical names and frequencies of occurrence were recorded.

(d) Within $15 \mathrm{~m}$ radius, all trees and shrubs with $\mathrm{DBH} \geq$ $20 \mathrm{~cm}$, their local and botanical names and frequencies of occurrence were recorded.

Other useful information about the plots that were recorded included date of measurement, Geographical Positioning System (GPS) readings, and indicators for anthropogenic disturbances.

The socioeconomic survey was done in the three randomly selected villages close to the forest, namely, Mangwi, Muyuyu, and Mkupuka. The work started with the reconnaissance and Participatory Rural Appraisal (PRA) in order to get an overview of the study area and modify the study questions. Systematic sampling was adopted in selecting the respondents so as to include people of different age, gender, and wealth categories, as reflected from PRA results. The second phase involved the administration of structured questionnaires so that 30 households from each of the sample villages were interviewed using a sampling intensity of $5 \%$. Key informants such as village leaders, extension staff, NGOs, various community groups (i.e., environmental committees, the youth, women, etc.), and district officials were also interviewed using checklists of probe questions to supplement information collected from the households.

Secondary information including village demographic data and previous survey reports was collected from village registries, the libraries of district, and various research institutions.

2.3. Data Analysis. The GIS data was analysed by the use of Arc View 1.3, and ERDAS Imagine Software, Version 8.3.1 programs to understand the major forest vegetation types and other land uses. 


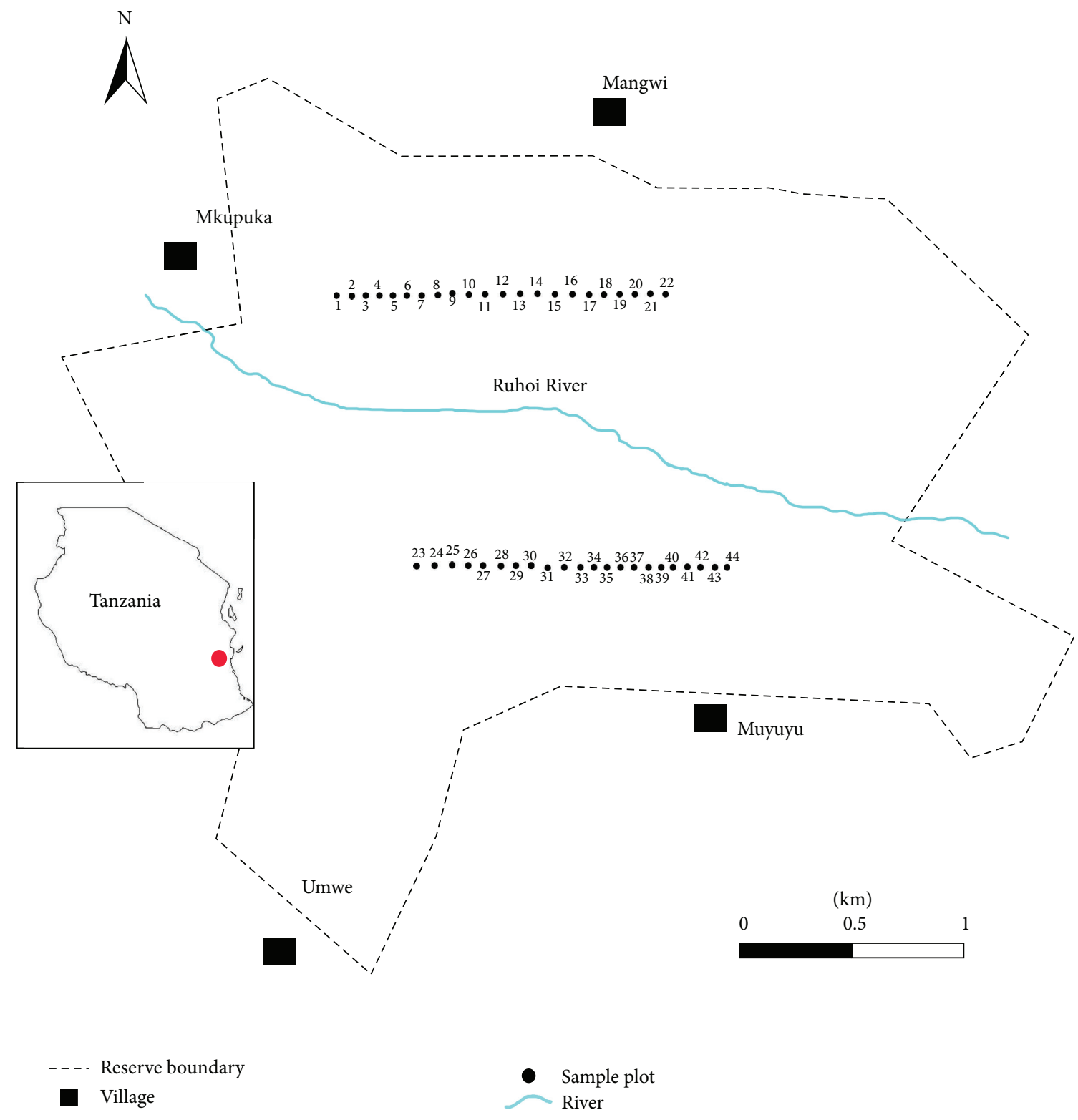

Figure 1: Map of the study area.

We determined species importance value index (IVI) from data on basal area, frequency, and density of tree species in both major strata. According to [17], basal area measures the area occupied by the stems of trees, while species frequency and density are important to measure distribution of species within the population. Computation of species dominance was done using the following formula:

$$
\mathrm{ID}=\sum\left(\frac{n_{i}}{N}\right)^{2}
$$

where ID is Index of Dominance, $n_{i}$ is important value index of each individual species, and $N$ is total Importance value index of all species. The greater the value of ID, the stronger the community is dominated by one or few species only.
The status of species diversity and richness data were analyzed by use of Shannon diversity index as summarized in the following formula:

$$
H=-\sum_{i=1}^{s} p i \log p i,
$$

where $H^{\prime}$ is the Shannon-Wiener biodiversity index, $\log _{e}$ is the natural $\log$ of $p i, s$ is total number of species in the community and $p i$ is proportion of $s$ made up of the $i$ th species. The larger the value of " $H$ " the greater the diversity and vice versa. According to [17], diversity indices provide more information about community composition than simply species richness by taking into account relative abundance of different species. The regeneration potential of NFR was analyzed from tree species with DBH less than $5 \mathrm{~cm}$ 
TABle 1: Age-sex distribution of respondents $(n=90)$.

\begin{tabular}{lcccc}
\hline Age range & Female & Male & Total & $\%$ \\
\hline $0-19$ & $5(71.4 \%)$ & $2(28.6 \%)$ & 7 & 8 \\
$20-40$ & $25(35.2 \%)$ & $46(64.8 \%)$ & 71 & 79 \\
$40-60+$ & $8(66.7 \%)$ & $4(33.3 \%)$ & 12 & 13 \\
\hline
\end{tabular}

Own survey, 2007.

TABLE 2: Relationship between size of farms and yield of cassava.

\begin{tabular}{|c|c|c|c|c|}
\hline \multirow{2}{*}{$\begin{array}{l}\text { Land holdings } \\
\text { (Acre) }\end{array}$} & \multicolumn{3}{|c|}{ Number of bags of cassava } & \multirow{2}{*}{ Total } \\
\hline & $<50(\%)$ & $50-100(\%)$ & $<100(\%)$ & \\
\hline Up to 5 & $5(26)$ & $10(52.6)$ & $4(21)$ & 19 \\
\hline 5 to 10 & $8(29.6)$ & $14(51.8)$ & $5(18.5)$ & 27 \\
\hline 10 to 15 & $6(28.6)$ & $7(33.3)$ & $8(38.09)$ & 21 \\
\hline Above 15 & $5(21.7)$ & $8(34.78)$ & $10(43.5)$ & 23 \\
\hline Total & $24(26.7)$ & 39 (43.3) & $27(30)$ & $90(100)$ \\
\hline
\end{tabular}

Source: own survey, 2007.

Chi-square $=5.5$ and NS, DF $=6$ at $P=0.05$.

measured in the 2 meters radius of the sample plots in both strata.

Socioeconomic data were analyzed by a combination of qualitative and quantitative methods. Qualitative data were analyzed using content analysis [18], whereas quantitative data were analyzed with the aid of Statistical Package for Social Sciences (SPSS) version 16 and Excel Spread Sheet (ESS) 2003.

\section{Results and Discussion}

3.1. Social-Economic Factors Affecting the Biodiversity of NFR. Response from key informants revealed that economic factors were most significant to degradation of NFR. Other important factors were demographic and institutional relating issues. Economic activities mostly reported by communities were logging (30\%), charcoaling (21\%), and shifting cultivation (20\%) as shown in Figure 2.

The proportion of males (64.8\%) was almost twice that of females within the middle aged group (Table 1). Being at this active age, the majority of men around NFR fit well with harsh and stressful forest activities such as felling down trees, carrying logs, and preparing charcoal pits. Similarly, it has been observed that males can easily dare to travel far from home for some days looking for bigger-sized trees or high quality timber [9]. In line with this finding, [10] commented that women are less involved in forest activities because of being responsible of several domestic duties including looking after children and cooking for the families.

Further to this, it was found that most villagers' farms were not productive enough to sustain their food requirement and/or selling the excess as a means of generating household income (Table 2). Cassava is the main food crop grown at Rufiji District followed by maize and cowpea [9]. Number of reasons were mentioned by farmers with regard to low agricultural productivity around NFR. For example, 68\% of household respondents revealed that they have not been

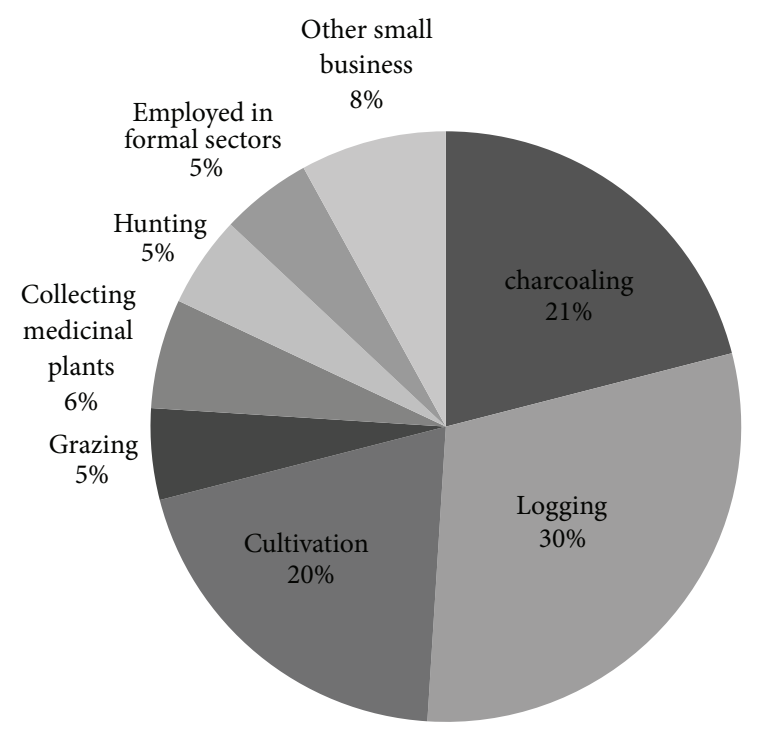

FIGURE 2: Major income sources of communities around Ngumburuni Forest Reserve.

visited by agriculture extension officer or being invited to workshops for the past three years. According to [3], most smallholder farmers in developing countries lack basic agricultural skills important for sustaining food production or adapting environmental challenges brought by climatic changes. Encroaching and clearing part of the forest for establishing new farms were reported by District Forest Officer as the strategy used by villagers to acquire fertile land that will substitute low yield realized in their own traditional farms. Worse enough, these plots are abandoned after being used for a short time. A similar practice has been reported in Zambia, whereby a shifting cultivation practice locally known as Chitemene involves clearing and burning part of the forest for crop production [3].

NFR has, for many years, been reported to be one of the important timber extraction hotspots in Southern Tanzania [12] following increasing demand of hard wood in international trade [19]. Local communities around NFR, on the other hand, also prefer some forest trees species for construction and firewood. Seventy eight (78\%) of the household respondents indicated that an average-sized rural house would roughly need between 200 to 300 poles which last up to five years. This short life span implies that communities will need to access the forest more frequently looking for poles among the shrub species and regenerating stems of tree species [11].

3.2. Tree Composition and Species Abundance. We recorded a total of 63 species from both strata within NFR whereby Hyphaene compressa was the most abundant followed by Vitex doniana, Euclea divinorum Syzygium cuminii, Acacis nigrescens, Grewia trichocarpa, Albizia versicolor, and Lannea schweinfurthii. It was also noted that over $63 \%$ of the species were in degraded forest while only $37 \%$ were found in closed forest (Table 1). This indicates that there is more species diversity in disturbed forest compared to undisturbed forest 
TABLE 3: Biodiversity characteristics of trees and shrubs in both disturbed and undisturbed forests.

\begin{tabular}{lccc}
\hline Parameter & Undisturbed forest & Disturbed forest & Computed $F$ \\
\hline Species richness (\%) & 37 & 63 & $71.3^{*}$ \\
Density of regenerants (\%) & 60 & 40 & $89.3^{*}$ \\
Stem per ha & 554 & 390 & $12.3^{*}$ \\
Shannon index $(H)$ & 2 & 3.7 & $42.46^{*}$ \\
Index of dominance & 0.09 & 0.026 & $97.7^{*}$ \\
\hline
\end{tabular}

Source: own survey, 2007.

$F(1,42)=4.07 ; P<0.05$.

area, most likely caused by ongoing disturbances. According to [17] opening forest canopy creates wider gaps which enhance emergence of suppressed understory species.

Data on tree density and basal area also confirm ongoing disturbances within NFR. It was noted that there was $33.4 \%$ decline in density of all large trees useful for timber and charcoal production in disturbed area. As responded by key informant, engagement of the local community to commercial logging and charcoal production has increased tremendously since 2000 when government improved road infrastructures within Rufiji district. Massive tons of logs have been exported to South Asia and European countries from Rufiji District through Dar es Salaam Port which is about $120 \mathrm{~km}$ from the forest [12]. This finding is comparable to that observed by [13] whereby selective logging in Cambodia also reduced the mean basal area and tree densities of the forest much in logged forest compared to unlogged one.

3.3. Species Diversity and Dominance. The results on the species diversity and species dominance are presented in Table 3, which confirm that the status of forest biodiversity between the two strata is differing significantly. It was noted that there is less tree species diversity in closed forest stratum compared to disturbed stratum. Probably, this is influenced by pioneer species characterizing the underground seed bank than what is being indicated by the standing vegetation of the two strata. The lower index of dominance in the disturbed forest further confirms imbalance in species distribution within the disturbed stratum as a result of the differential species preferences in the harvesting. Most loggers prefer trees with large diameter and straight shape. Species like Milia excels and Pterocarpus angolensis have been reported to be endangered in most Miombo woodlands in Tanzania. [20] observed that $P$. angolensis could nearly be completely depleted in the foreseeable future in Msaginia Forest Reserve in western Tanzania. A similar observation was made by [21] in Swagaswaga Game Reserve in Kondoa, Tanzania, where selective cutting has exhausted valuable timber species leading to a shift towards cutting smaller diameter trees and less preferable ones like Brachystegia spiciformis. However, the values of tree diversity indices indicate that both strata have high value of species richness at NFR. According to [22], Shannon's index of value greater than 2 is assigned as medium to high diversity. The higher value of diversity in disturbed stratum implies that disturbances in NFR open up the forest canopy thereby creating favourable conditions for the emergency of new species or regrowth of suppressed

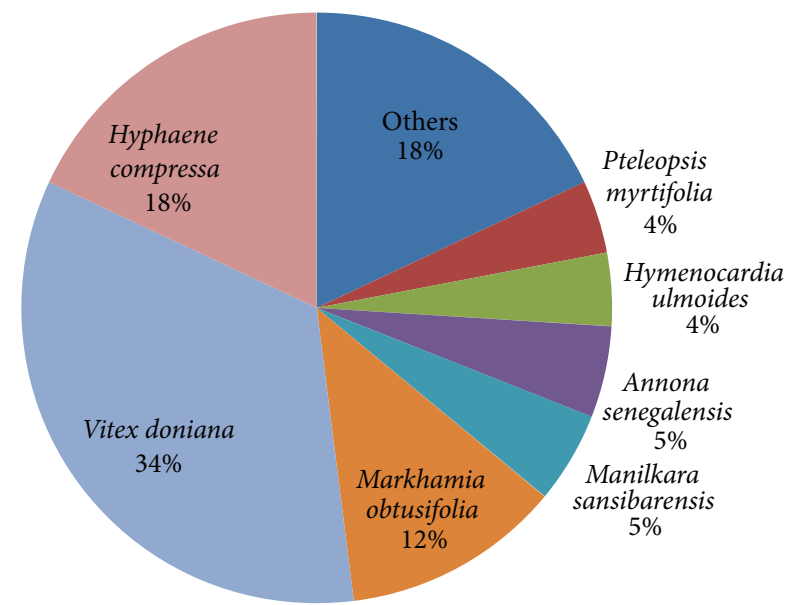

FIgURE 3: Percentage distribution of regenerants in closed forest stratum.

species [23]. In degraded stratum new fifteen emergent species had been observed which, probably, contributed to higher plant diversity. The closed forest stratum of NFR, however, still harbors important biodiversity and constitutes a unique habitat for rare or threatened species. During the Songas pipeline survey Aframomum orientale, a plant endemic to Rufiji and Mkuranga districts, and two orchids, Microcoelia exilis and Microcoelia megalorrhiza, were found [24].

The values of index of dominance from this study (Table 3) indicated that few species in the closed stratum dominated others. These include the following tree species: Hyphaene compressa, Euclea divinorum, Syzygium cuminii, Antidesma venosum, and Albizia versicolor. The values of indices of dominance in degraded strata compare well with values of 0.005 and 0.04 in the Usambara and Ulugurus, respectively [13]. These forests have been subjected to human disturbances such as logging and other encroachments in the past. According to [25], high levels of extraction of live wood tend to affect forest composition and structure, leading to alteration in the forest ecosystem functions and imminent succession collapse. Species which maintain major functions of the ecosystems are referred to as keystone species. Removing even a few of these species tends to affect the functioning of ecosystems [26]. 


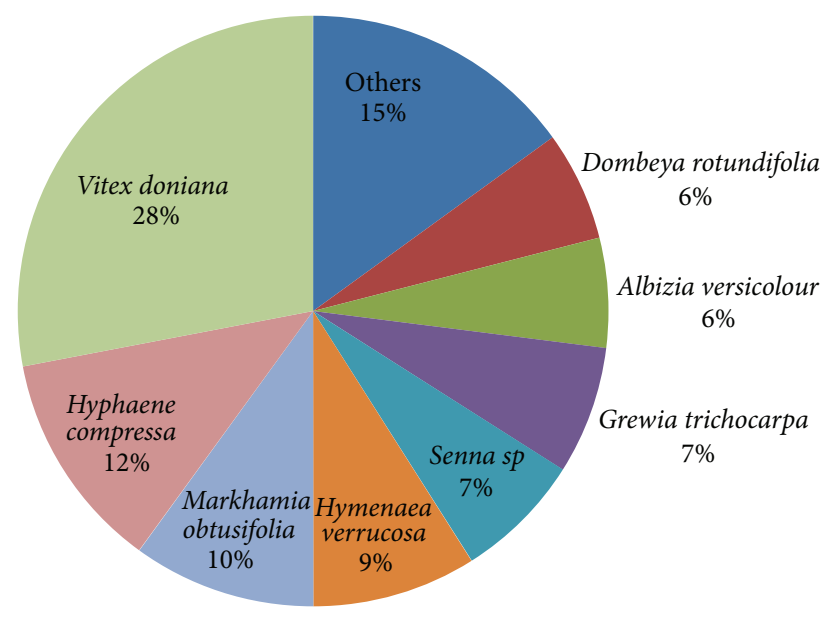

FIgURE 4: Percentage distribution of regenerants in open forest stratum.

3.4. Distribution of Regenerants. The results on the regeneration status of the trees in the forest reserve are presented in Table 3 and Figures 3 and 4. It was noted that the regeneration in the undisturbed forest stratum was $60 \%$ of the total indicating that the degradation of Ngumburuni Forest Reserve is likely to escalate with the continued forest encroachment. This could result in impairment in the overall regeneration potential of the reserve and further impacting on the fast degrading tree species diversity. It is likely that the opened canopy in NFR allows much more sunlight to reach forest base and break the seed dormancies and/or promote fast growth of the young trees. It was observed that in both forest strata the most abundant tree species (i.e., $V$. doniana, $H$. compressa, and M. obtusifolia) are proportionally dominating the regeneration populations.

The higher regeneration status of tree species within the closed stratum is different from that found by [27] who noted that the regeneration of tree species was decreasing from the main road towards the centre of the forest reserve. The situation at Ngumburuni may be caused by the more frequently occurring fires which cause deaths to some of the seeds in the soil. [15] had the same observation in Herena Forest Reserve in Ethiopia whereby the proportion of germinating seeds from unburned soil sample was higher than in the burned one. It can be realized, therefore, that many trees at NFR are germinating by means of seeds which are susceptible to fires.

\section{Conclusion}

Human disturbance had a significant effect on forest structure and composition in Ngumburuni Forest Reserve leading to lowered densities of useful plants especially important timber trees. Fire was observed to be the central part of several disturbances reported to take place in Ngumburuni such as shifting cultivation, charcoaling, and logging. It was further noted that poor economic status among many villagers was closely connected to accessibility to the forest. Despite the fact that NFR still holds an important proportion of tree species richness, there is a need to prevent further human disturbances within the forest so that it can sustain its ecological functioning. Strict law enforcement on exploitation of forest resources, community education, and promotion of alternative income generating activities should be encouraged. Similarly, restoration of the ecosystem through reforestation in most degraded areas of the forest should, also, be given immediate attention by forest management authorities.

\section{References}

[1] C. H. Cannon, D. R. Peart, and M. Leighton, "Tree species diversity in commercially logged Bornean rainforest," Science, vol. 281, no. 5381, pp. 1366-1368, 1998.

[2] F. E. Putz, K. H. Redif, and J. G. Robinson, Biodiversity Conservation in the Context of Tropical Forest Management, The World Bank Environmental Department, Washington, DC, USA, 2000.

[3] C. Shackleton and S. Shackleton, "The importance of nontimber forest products in rural livelihood security and as safety nets: a review of evidence from South Africa," South African Journal of Science, vol. 100, no. 11-12, pp. 658-664, 2004.

[4] J. S. Denslow, "Disturbance and diversity in tropical rain forests: the density effect," Ecological Applications, vol. 5, no. 4, pp. 962968, 1995.

[5] K. Eichhorn, "The plant community of Sungai Wain, East Kalimantan, Indonesia: phytogeographical status and local variation," Blumea Supplement, vol. 18, pp. 15-35, 2006.

[6] M. A. Pinard, M. G. Barker, and J. Tay, "Soil disturbance and post-logging forest recovery on bulldozer paths in Sabah, Malaysia," Forest Ecology and Management, vol. 130, no. 1-3, pp. 213-225, 2000.

[7] S. A. Pickett, "Drivers and dynamics of change in biodiversity," in Global Biodiversity Assessment, V. H. Heywood and R. T. Watson, Eds., pp. 311-318, United Nations Environment Programme, Cambridge, UK, 1995.

[8] J. Kimaro and L. Lulandala, "Contribution of non-timber forest products to poverty alleviation and forest conservation in Rufiji District-Tanzania," Journal of Livestock Research For Rural Development Livestock Research For Rural Development, vol. 25, no. $5,2013$.

[9] REMP, Report on Strategy for Assessment of the Woody Vegetation of the Rufiji District, REMP, Rufiji, Tanzania, 2003.

[10] B. K. Kaale, H. K. Ramadhani, B. T. Kimaryo, R. S. Maro, and H. Abdi, Participatory Forest Resource Assessment, Misitu Yetu Project, CARE Tanzania, Dar es Salaam, Tanzania, 2002.

[11] N. D. Burgess and G. P. Clarke, Coastal Forest of Eastern Africa, IUCN, Gland, Switzerland, 2000.

[12] S. A. H. Milledge and B. K. Kaale, Bridging the Gap-Linking Timber Trade with Infrastructural Development in Southern Tanzania: Baseline Data before Completion of the Mkapa Bridge, TRAFFIC East/Southern Africa, Dar es Salaam, Tanzania, 2005.

[13] P. K. T. Munishi and T. H. Shear, "Rainfall interception and partitioning in afromontane rain forests of the Eastern Arc Mountains, Tanzania: implications for water conservation," Journal of Tropical Forest Science, vol. 17, no. 3, pp. 355-365, 2005.

[14] S. M. Philip, Measuring Trees and Forests, CAB International, Wallingford, UK, 2nd edition, 1994. 
[15] R. E. Malimbwi, “An Inventory Report of the Principle Timber Resources of the Miombo and Riverine Woodlands and Forests of Rufiji District," Tech. Rep. 12, REMP, Utete, Tanzania, 2000.

[16] C. J. Krebs, Ecological Methodology, Hamper Collins, New York, NY, USA, 1989.

[17] R. A. Giliba, E. K. Boon, C. J. Kayombo, E. B. Musamba, A. M. Kashindye, and P. F. Shayo, "Species composition, richness and diversity in Miombo Woodland of Bereku Forest Reserve Tanzania," Journal of Biodiversity, vol. 2, no. 1, pp. 1-7, 2011.

[18] G. C. Kajembe, Indiginous Management Systems as a Basic for Community Forestry in Tanzania. A Case Study of Dodoma Urban and Lushoto Districts, Wageningen Agricultural University, Wageningen, The Netherlands, 1994.

[19] LLC, "Illegal" Loging and Global Wood Markerts: Seneca Creek Associates, LLC and Wood Resources International, LLC, 2004.

[20] M. W. Schwartz, T. M. Caro, and T. Banda-Sakala, "Assessing the sustainability of harvest of Pterocarpus angolensis in Rukwa Region, Tanzania," Forest Ecology and Management, vol. 170, no. 1-3, pp. 259-269, 2002.

[21] N. F. Madulu, Population Dynamics and Sustainable Conservation of Protected Areas in Tanzania. the Case of Swagaswaga Game Reserve in Kondoa District, Department of Earth Sciences, Programme for Applied Environmental Impact Assessment. Villavägen, Uppsala, Sweden, 2001.

[22] G. M. Barbour, H. J. Burk, and W. D. Pitts, Terrestrial Plant Ecology, The Benjamin/Cummings Publishing, Redwood City, Calif, USA, 1987.

[23] R. S. Ambasht, A Survey of the Avifauna of Chome Forest Reserve, South Pare Mountains, North-East Tanzania, East African Cross-Border Biodiversty Project, Arusha, Tanzania, 2001.

[24] Songas, "Songo songo gas to electricity project, environmental studies," Final Report, SONGAS, Dar es Salaam, Tanzania, 2003.

[25] J. Obiri, M. Lawes, and M. Mukolwe, "The dynamics and sustainable use of high-value tree species of the coastal Pondoland forests of the Eastern Cape Province, South Africa," Forest Ecology and Management, vol. 166, no. 1-3, pp. 131-148, 2002.

[26] T. Jackson, K. Begg, and S. Parkinson, Flexibility in Climate Policy-Making the Kyoto Mechanisim Work, Earthscan, London, UK, 2001.

[27] G. Tesfaye, D. Teketay, Y. Assefa, and M. Fetene, “The impact of fire on the soil seed bank and regeneration of Harenna Forest, southeastern Ethiopia," Mountain Research and Development, vol. 24, no. 4, pp. 354-361, 2004. 

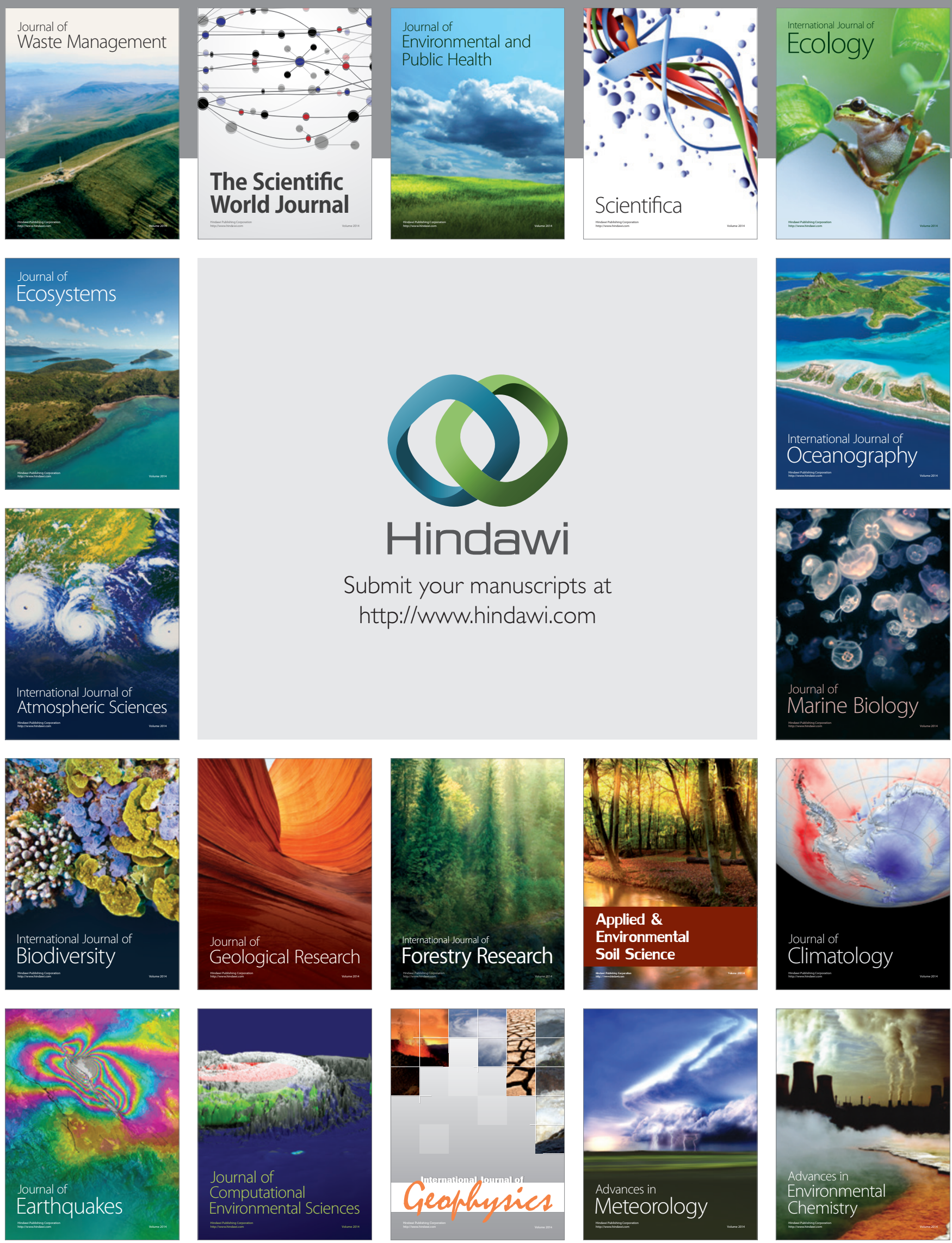